\title{
Loss of Plasticity in the D2-Accumbens Pallidal Pathway Promotes Cocaine Seeking
}

\author{
- $J a s p e r$ A. Heinsbroek, ${ }^{1 \star}$ Daniela N. Neuhofer, ${ }^{1 *}$ William C. Griffin, III, ${ }^{2}$ Griffin S. Siegel, ${ }^{2}$ Ana-Clara Bobadilla, ${ }^{1}$ \\ Yonatan M. Kupchik, ${ }^{3} \uparrow$ and $\odot$ Peter W. Kalivas ${ }^{1,2} \uparrow$ \\ ${ }^{1}$ Department of Neuroscience and ${ }^{2}$ Department of Psychiatry and Behavioral Science, Medical University of South Carolina, Charleston, South Carolina \\ 29425, and ${ }^{3}$ Department of Neuroscience, Hebrew University, Jerusalem, 91120 Israel
}

Distinct populations of D1- and D2-dopamine receptor-expressing medium spiny neurons (D1-/D2-MSNs) comprise the nucleus accumbens, and activity in D1-MSNs promotes, whereas activity in D2-MSNs inhibits, motivated behaviors. We used chemogenetics to extend D1-/D2-MSN cell specific regulation to cue-reinstated cocaine seeking in a mouse model of self-administration and relapse, and found that either increasing activity in D1-MSNs or decreasing activity in D2-MSNs augmented cue-induced reinstatement. Both D1- and D2-MSNs provide substantial GABAergic innervation to the ventral pallidum, and chemogenetic inhibition of ventral pallidal neurons blocked the augmented reinstatement elicited by chemogenetic regulation of either D1- or D2-MSNs. Because D1- and D2-MSNs innervate overlapping populations of ventral pallidal neurons, we next used optogenetics to examine whether changes in synaptic plasticity in D1- versus D2-MSN GABAergic synapses in the ventral pallidum could explain the differential regulation of VP activity. In mice trained to self-administer cocaine, GABAergic LTD was abolished in D2-, but not in D1-MSN synapses. A $\mu$ opioid receptor antagonist restored GABA currents in D2-, but not D1-MSN synapses of cocaine-trained mice, indicating that increased enkephalin tone on presynaptic $\mu$ opioid receptors was responsible for occluding the LTD. These results identify a behavioral function for D1-MSN innervation of the ventral pallidum, and suggest that losing $\mathrm{LTD}_{\mathrm{GABA}}$ in D2-MSN, but not D1-MSN input to ventral pallidum may promote cue-induced reinstatement of cocaine-seeking.

Key words: accumbens; cocaine; GABA; LTD; pallidum; relapse

Significance Statement

More than $90 \%$ of ventral striatum is composed of two cell types, those expressing dopamine D1 or D2 receptors, which exert opposing roles on motivated behavior. Both cell types send GABAergic projections to the ventral pallidum and were found to differentially promote cue-induced reinstatement of cocaine seeking via the ventral pallidum. Furthermore, after cocaine selfadministration, synaptic plasticity was selectively lost in D2, but not D1 inputs to the ventral pallidum. The selective impairment in D2 afferents may promote the influence of D1 inputs to drive relapse to cocaine seeking.

\section{Introduction}

The striatum is composed of D1- and D2-dopamine receptorexpressing medium spiny neurons (D1- and D2-MSNs) that

\footnotetext{
Received Aug. 22, 2016; revised Nov. 15, 2016; accepted Nov. 28, 2016.

Author contributions: J.A.H., D.N.N., Y.M.K., and P.W.K. designed research; J.A.H., D.N.N., W.C.G., G.S.S., A.C.B., and Y.M.K. performed research; J.A.H., D.N.N., Y.M.K., and P.W.K. analyzed data; J.A.H. and P.W.K. wrote the paper.

This research was supported in part by United States Public Health Service Grants DA012512, DA003906, and DA015369. We thank Dr. Jamie Peters and the members of the P.W.K. laboratory for helpful comments on the manuscript; and Victoria Chareunsouk and Lauryn Luderman for technical assistance.

The authors declare no competing financial interests.

*J.A.H. and D.N.N. contributed equally to this study as first authors.

TY.M.K. and P.W.K. contributed equally to this study as senior authors.

Correspondence should be addressed to either Dr. Jasper A. Heinsbroek or Dr. Peter W. Kalivas, Medical

University of South Carolina, Drug Discovery Building 223, 70 President Street, Charleston, SC 29425. E-mail: heinsbro@musc.edu or kalivasp@musc.edu.

DOI:10.1523/JNEUROSCI.2659-16.2016

Copyright $\odot 2017$ the authors $\quad 0270-6474 / 17 / 370757-11 \$ 15.00 / 0$
}

canonically project through distinct circuits. Thus, D1-MSNs innervate the ventral mesencephalon via the "direct" pathway and D2-MSNs innervate the globus pallidus via the "indirect" pathway (Gerfen and Surmeier, 2011). Contrasting this view, the nucleus accumbens, which occupies the ventromedial quadrant of the rodent striatum (Zahm and Heimer, 1988), has abundant D1- and D2-MSN innervation of the ventral portion of the globus pallidus, the ventral pallidum (VP) (Lu et al., 1998; Kupchik et al., 2015).

The nucleus accumbens and its projection to the VP regulates the expression of behavioral responding to motivationally relevant stimuli, including addictive drugs (Koob and Volkow, 2010; Floresco, 2015; Laurent et al., 2015), and the advent of D1- and D2-Cre transgenic mice has allowed investigators to selectively probe the role of D1- and D2-MSNs in regulating behavior (Lobo 
and Nestler, 2011; Kravitz et al., 2012; Britt and Bonci, 2013). Activating D1-MSNs promotes the execution of motivated behaviors, such as sucrose consumption and use of addictive drugs, whereas stimulating D2-MSNs has the opposite effect (Lobo et al., 2010; Bock et al., 2013; Francis et al., 2015). Also, cocaine exposure increases the strength of synaptic inputs onto D1MSNs, which has been linked to enhanced motivation to use and seek cocaine (Pascoli et al., 2011, 2014; Bock et al., 2013). These studies in transgenic mice are generally interpreted to indicate distinct behavioral functions for D1-MSN direct projections to the ventral mesencephalon and the D2-MSN indirect projections to the VP. However, because both D1- and D2-MSNs strongly innervate the VP, we hypothesized that cue-induced cocaine seeking is regulated by both D1- and D2-MSN innervation of the VP. To test this hypothesis, we used a chemogenetic strategy using designer receptors exclusively activated by designer drugs (DREADDs) coupled to either Gs (rM3D) or Gi (hM4D), to mimic the G-protein signaling of dopamine onto D1- or D2receptors, respectively (Armbruster et al., 2007; Farrell et al., 2013; Goto et al., 2015; Roth, 2016). To test the propensity of discrete stimuli to elicit drug seeking behavior, we used a mouse model of cocaine self-administration and extinction where the animal can press a lever to obtain an intravenous delivery of drug over the course of multiple days, after which this behavior is extinguished in subsequent sessions without drug availability. In this model, returning drug-paired cues to each lever press reinvigorates drug-seeking behavior (Fuchs et al., 2003; Panlilio and Goldberg, 2007). Combining these methods, we found that both the D1 and D2 inputs to the VP regulate cocaine seeking, with activity in the D1 pathway facilitating and D2 pathway reducing cued reinstatement.

Because both D1- and D2-MSN terminals release GABA onto the same VP neurons (Kupchik et al., 2015), we investigated whether differences in synaptic plasticity might underlie these behavioral effects using an optogenetic strategy in D1- and D2Cre mice. After extinction of cocaine self-administration, there was a loss of GABAergic LTD ( $\left.\operatorname{LTD}_{\mathrm{GABA}}\right)$ in synapses of the D2, not D1, pathway to the VP, and this loss was likely mediated by elevated inhibitory tone on presynaptic $\mu$ opioid receptors (MORs) on D2 pathway afferents, which occluded the induction of LT$\mathrm{D}_{\mathrm{GABA}}$. Together, our data show a behavioral function for the D1 pathway to the VP, and that impaired synaptic plasticity in D2 pathway synapses may predispose toward enhanced reinstatement of cocaine seeking via the D1-MSN innervation of the VP.

\section{Materials and Methods}

Animals. D1- and D2-Cre BAC transgenic lines were obtained from N. Heintz, P. Greengard (Rockefeller University), C. Gerfen (National Institute of Mental Health), and NINDS/GENSAT (www.gensat.org). These transgenic mice express Cre recombinase under control of the dopamine D1 receptor promoter (Drd1a, line FK150, RRID:MMRRC_ 029178-UCD) or dopamine D2 receptor promoter (Drd2, line ER44, RRID:MMRRC_017263-UCD). Mice were bred in house and periodically outbred with wild-type C57BL/6J (The Jackson Laboratory). Before experimental procedures, mice were group housed, fed ad libitum, and maintained in a humidity- and temperature-controlled environment. All experiments occurred during the dark phase and were conducted in accordance with the National Institute of Health's Guidelines for the care and use of laboratory animals. All procedures were approved by the Institutional Animal Care and Use Committee at the Medical University of South Carolina.

Surgery. Mice (20-30 g) of either sex were anesthetized with isoflurane (induction 3\%-5\% v/v, maintenance 1\%-2\% v/v) and implanted with an indwelling jugular catheter connected to a head-mounted entry port as described previously (Griffin and Middaugh, 2003). In brief, the neck of the mouse was incised and the tip of the catheter was inserted $\sim 5 \mathrm{~mm}$ from the clavicle between 10 and $12 \mathrm{~mm}$ into the vein. The catheter was sutured in place, and the entry port was secured to the head of the mouse using dental cement. Cephazolin (200 mg/kg, i.v.) was administered acutely to prevent infection, and carprofen $(5 \mathrm{mg} / \mathrm{kg}$, s.c. $)$ and topical antibacterial ointment were given postoperatively for 2-3 d following surgery. Catheters were flushed twice daily with heparinized (100 units/ $\mathrm{ml}$ ) normal saline.

For viral microinfusions, microinjection needles (33 Ga; Plastics One) were connected to a microinjection pump and injections $(300 \mathrm{nl})$ were delivered at a rate of $50 \mathrm{nl} / \mathrm{min}$. Afterward injectors were left in place for 10 min to allow for diffusion of the virus and then slowly retracted. To achieve cell-type specific expression, double-floxed inverted orientation (DIO) transgenes were introduced into Cre recombinase-expressing neurons using AAV viral vectors (AAV2-hSyn-DIO-hM4D-mCherry; titer $\sim 4.6 \times 10^{12}$; AAV2-hSyn-DIO-rM3D-mCherry, titer $\sim 6.5 \times 10^{12}$; AAV2-EF1a-hChR2(H134R)-eYFP, titer $\sim 6.0 \times 10^{12}$ ) infused in the nucleus accumbens (in mm from bregma: anteroposterior: 1.5; mediolateral: \pm 1.2 ; dorsoventral: -4.4$)$. Additionally, a nonfloxed vector was infused into the VP (in mm from bregma: anteroposterior: 0.2; mediolateral: 1.5; dorsoventral: - 4.9; AAV2-hSyn-HA-hM4D-IRES-mCitrine, titer $\sim 2.6 \times 10^{12}$ ). All vectors were generated by the University of North Carolina Vector Core. Following surgery, mice were single housed and given at least $3 \mathrm{~d}$ of recovery before the start of behavioral experiments, and a minimum of 3 weeks was used between surgery and slice electrophysiology or behavioral testing to allow for expression of viral vectors.

Cocaine self-administration, extinction, and reinstatement. Following surgery, catheters were maintained by flushing twice daily with heparinized saline throughout the procedure, and catheter patency was checked at the end of the self-administration phase for all mice by using the short-acting barbiturate Brevital (0.2 mg i.v.). Mice in which apparent signs of hypotonia were not observed within $3 \mathrm{~s}$ were excluded from the study. Mice were trained for $10-15 \mathrm{~d}$ on a fixed ratio 1 schedule of reinforcement during daily $2 \mathrm{~h}$ cocaine self-administration sessions until they reached criterion of at least $3 \mathrm{~d}$ of 15 cocaine infusions. During the first 3- 6 sessions, mice were mildly food restrained (to 90\%-95\% of their free feeding weight) to stimulate exploration of the operant box. During each session, presses on the active lever resulted in the infusion of cocaine ( $\sim 0.75 \mathrm{mg} / \mathrm{kg} /$ infusion, in sterile saline) paired with a compound stimulus ( $2 \mathrm{~s}$ tone + light), followed by a $20 \mathrm{~s}$ time-out period during which cocaine was unavailable. Yoked saline control mice received saline infusions and cue presentations in the same manner, independent of their own lever responding. Following self-administration, mice were extinguished for at least $10 \mathrm{~d}$ until criterion was reached (2 successive days $<20$ active lever presses/d) and given cue-induced reinstatement tests in counterbalanced order with at least $2 \mathrm{~d}$ of extinction training in between. Before each test mice were injected with CNO (1 mg/kg, i.p., Tocris Bioscience, \#4936) or vehicle (sterile saline) and returned to their homecage for $30 \mathrm{~min}$. Cue-induced reinstatement tests lasted $2 \mathrm{~h}$ and responding on the active lever produced the tone + light cue previously paired with cocaine on the same $20 \mathrm{~s}$ fixed interval time-out schedule. After self-administration, mice for electrophysiological experiments were run for at least 10 daily extinction session, and recordings were performed $24 \mathrm{~h}$ after the last session

Sucrose self-administration, extinction, and reinstatement. Following stereotaxic surgery, mice were mildly food deprived ( 90\%-95\% of free feeding weight) and trained to self-administer sucrose pellets (14 mg, BioServ) on a fixed ratio 1 schedule of reinforcement wherein active lever pressing resulted in the delivery of a sucrose pellet in a food receptacle and presentation of the same compound (light + tone) cue as for the cocaine studies. All mice self-administered sucrose for at least $12 \mathrm{~d}$ followed by $10 \mathrm{~d}$ of extinction training. Afterward mice received an injection of CNO ( $1 \mathrm{mg} / \mathrm{kg}$, i.p.) or vehicle (sterile saline) and were returned to their home cage for $30 \mathrm{~min}$ before reinstatement testing. During cueinduced reinstatement, active lever presses resulted in the presentation of the compound stimulus that previously signaled sucrose delivery. During cue- and pellet-primed reinstatement in the first $10 \mathrm{~min}$ of the ses- 
sion, every 2 min a pellet was delivered noncontingently, followed by another noncontingent pellet delivered every 20 min during the rest of the session.

Slice preparation and whole-cell patch-clamp recording. Fresh VP slices (220 $\mu \mathrm{m}$; VT1200S Leica vibratome) were collected into a vial containing aCSF as follows (in mm: $126 \mathrm{NaCl}, 1.4 \mathrm{NaH}_{2} \mathrm{PO}_{4}, 25 \mathrm{NaHCO}_{3}, 11$ glucose, $1.2 \mathrm{MgCl}_{2}, 2.4 \mathrm{CaCl}_{2}, 2.5 \mathrm{KCl}, 2.0$ sodium pyruvate, 0.4 ascorbic acid, bubbled with $95 \% \mathrm{O}_{2}$ and $5 \% \mathrm{CO}_{2}$ ) and a mixture of $5 \mathrm{~mm}$ kynurenic acid and $50 \mu \mathrm{M} \mathrm{D}-\mathrm{APV}$. Slices were kept at $22^{\circ} \mathrm{C}-24^{\circ} \mathrm{C}$ until they were used for recordings, and were constantly perfused with oxygenated aCSF heated to $32^{\circ} \mathrm{C}$ (TC-344B, Warner Instruments). Excitatory synaptic transmission was blocked with 6-cyano-7nitroquinoxaline-2,3-dione (CNQX; $10 \mu \mathrm{M}$ ). Neurons were visualized with a Zeiss Axioscope 2 FS plus microscope with a $40 \times$ objective. Recordings of synaptic currents were performed in voltage-clamp configuration at a membrane potential of $-80 \mathrm{mV}$ (Multiclamp 700B, Molecular Devices). Glass microelectrodes (1.5-2.5 $\mathrm{M} \Omega$ tip resistance) were prepared using a PC-10 vertical puller (Narishige) and filled with internal solution as follows (in mM: $68 \mathrm{KCl}, 65 \mathrm{D}$-gluconic acid potassium salt, 7.5 HEPES potassium, 1 EGTA, $1.25 \mathrm{MgCl}_{2}, 10 \mathrm{NaCl}, 2.0 \mathrm{MgATP}$, and 0.4 NaGTP; pH 7.2-7.3, $275 \mathrm{mOsm})$. Data were acquired at $10 \mathrm{kHz}$ and filtered at $2 \mathrm{kHz}$ using Axograph X software (Axograph Scientific). IPSCs were evoked optogenetically, and the stimulation intensity was set to evoke an IPSC with amplitudes within the dynamic range of each neuron (i.e., 30\%-70\% of maximal IPSCs, $200-900 \mathrm{pA}$ ). The light pulse was produced by a $460 \mathrm{~nm}$ LED (Mightex) that was transmitted on the slice through the microscope objective. For the LTD experiments, a highfrequency stimulation (HFS) protocol was delivered electrically via a bipolar stimulation electrode positioned 200-300 $\mu \mathrm{m}$ dorsomedial to the recorded cell. The HFS protocol consisted of three trains separated by $20 \mathrm{~s}$, each delivering 100 stimulations at $100 \mathrm{~Hz}$. The intensity $(100-600$ $\mu \mathrm{A}$ ) was set to elicit IPSCs of the same amplitude as for optically induced IPSCs from each neuron. Recordings of synaptic transmission were started $10 \mathrm{~min}$ after invading the cell to allow for internal solution diffusion to remote dendrites. Membrane capacitance and input resistance were calculated automatically from a $-2 \mathrm{mV}$ pulse (Axograph X software, Axograph Scientific). Recordings with unstable series resistance or with a series resistance $>20 \mathrm{M} \Omega$ were discarded.

Histology. Mice were transcardially perfused with ice-cold phosphate buffer $(0.1 \mathrm{M}, \mathrm{pH} 7.4)$, followed by $4 \%$ PFA solution. After extraction, brains were postfixed in 4\% PFA solution overnight and then transferred to $20 \%$ sucrose in PBS for an additional $24 \mathrm{~h}$. Brains were frozen on dry ice and sliced on a microtome at $35 \mu \mathrm{m}$. Slices were blocked in PBS containing 5\% normal goat serum, $2.5 \%$ BSA, and $0.25-0.5 \%$ Triton X-100, and incubated in primary antibody overnight (mouse anti-NeuN 1:1000, Millipore \#MAB377, RRID:AB_2298772; rabbit anti-dsRed, 1:1000, Clontech \#632496, RRID:AB_10013483; rabbit anti-DARPP-32, 1:1000, Abcam \#ab18551, RRID:AB_2284277; chicken anti-GFP, 1:500, Abcam \#ab13970, RRID:AB_300798; rabbit anti-metenkephalin, 1:1000, Immunostar \#20065, RRID:AB_572250) followed by $2 \mathrm{~h}$ incubation at room temperature in Alexa-conjugated secondary antibodies (Thermo Fisher, 1:1000). Images were acquired as stacks using a SP6 confocal microscope (Leica Microsystems), deconvolved (AutoQuant X2, MediaCybernetics), and visualized in Imaris (Bitplane).

Statistical analysis. All data are represented as mean \pm SEM. Statistical analyses were performed using Prism version 6.0 (GraphPad). Two-way repeated-measures ANOVA, one-way ANOVA, and paired and unpaired Student's $t$ tests were used for electrophysiological and behavioral data as specified in Results. One-sample $t$ test was used for normalized IPSC comparisons. Statistical significance was set at 0.05 .

\section{Results}

Cocaine self-administration and functional expression of genetic constructs in D1- and D2-Cre mice

D1- and D2-Cre mice underwent $12 \mathrm{~d}$ of cocaine self-administration or yoked-saline delivery followed by at least $10 \mathrm{~d}$ of extinction training ( $2 \mathrm{~h}$ each day; Fig. $1 A$ ). Infusion of cocaine was paired with the presentation of a compound light/tone cue.
A

D1-Cre

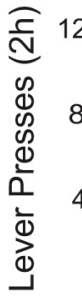
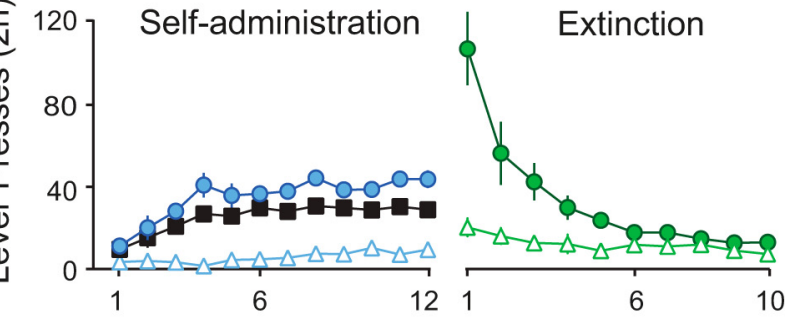

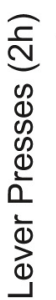

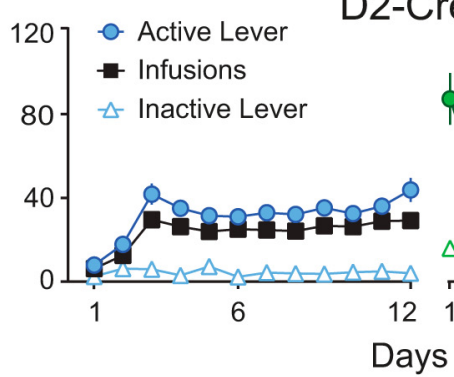

B
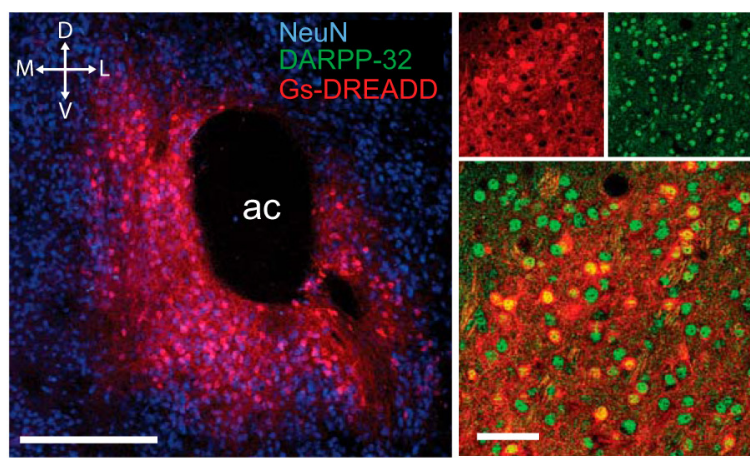

Figure 1. Cocaine self-administration and viral infection with optogenetic and chemogenetic transgenes in D1-Cre and D2-Cre mouse lines. A,D1-Cre $(n=27)$ and D2-Cre $(n=29)$ mice were trained to self-administer cocaine followed by extinction training. Note the burst of active lever responding on day 1 of extinction. $\boldsymbol{B}$, Coronal slice showing representative Gi-DREADD $\mathrm{hM} 4 \mathrm{D}$ expression in the accumbens core, and a higher-magnification inset showing that expression colabeled with the MSN marker DARPP-32. Left scale bar, $300 \mu \mathrm{m}$. Right scale bar, $50 \mu \mathrm{m}$. ac, Anterior commissure. Arrows indicate dorsoventral (DV) and mediolateral (ML) orientation.

\section{A}

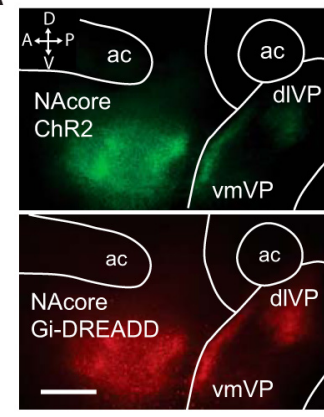

B

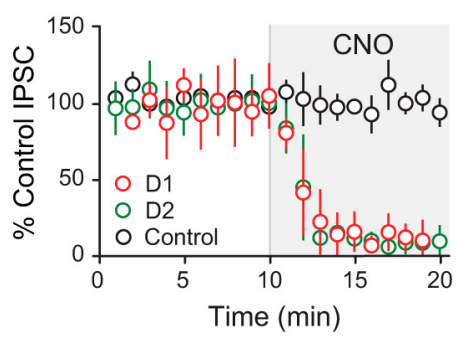

Figure 2. Chemogenetic inhibition of D1 and D2 terminals abolished optical elPSC in VP neurons. $\boldsymbol{A}$, Sagittal sections showing Gi-DREADD and ChR2 expression in the projection from the accumbens to the VP, in particular to the dorsolateral VP subcompartment (dIVP) and to a lesser extent the ventromedial subcompartment (vmVP). Scale bar, $300 \mu \mathrm{m}$. ac, Anterior commissure. Arrow and letters indicate anteroposterior (AP) and dorsoventral (DV) orientation. $\boldsymbol{B}$, Electrophysiological demonstration that optically evoked eIPSCs from D1 and D2 projections were inhibited by bath applying CNO $(1 \mu \mathrm{M})$. D1 projection $(n=6), \mathrm{D} 2$ projection $(n=5)$, and Control $(n=4)$ cells from non-DREADD-infected D1- and D2-MSN. 

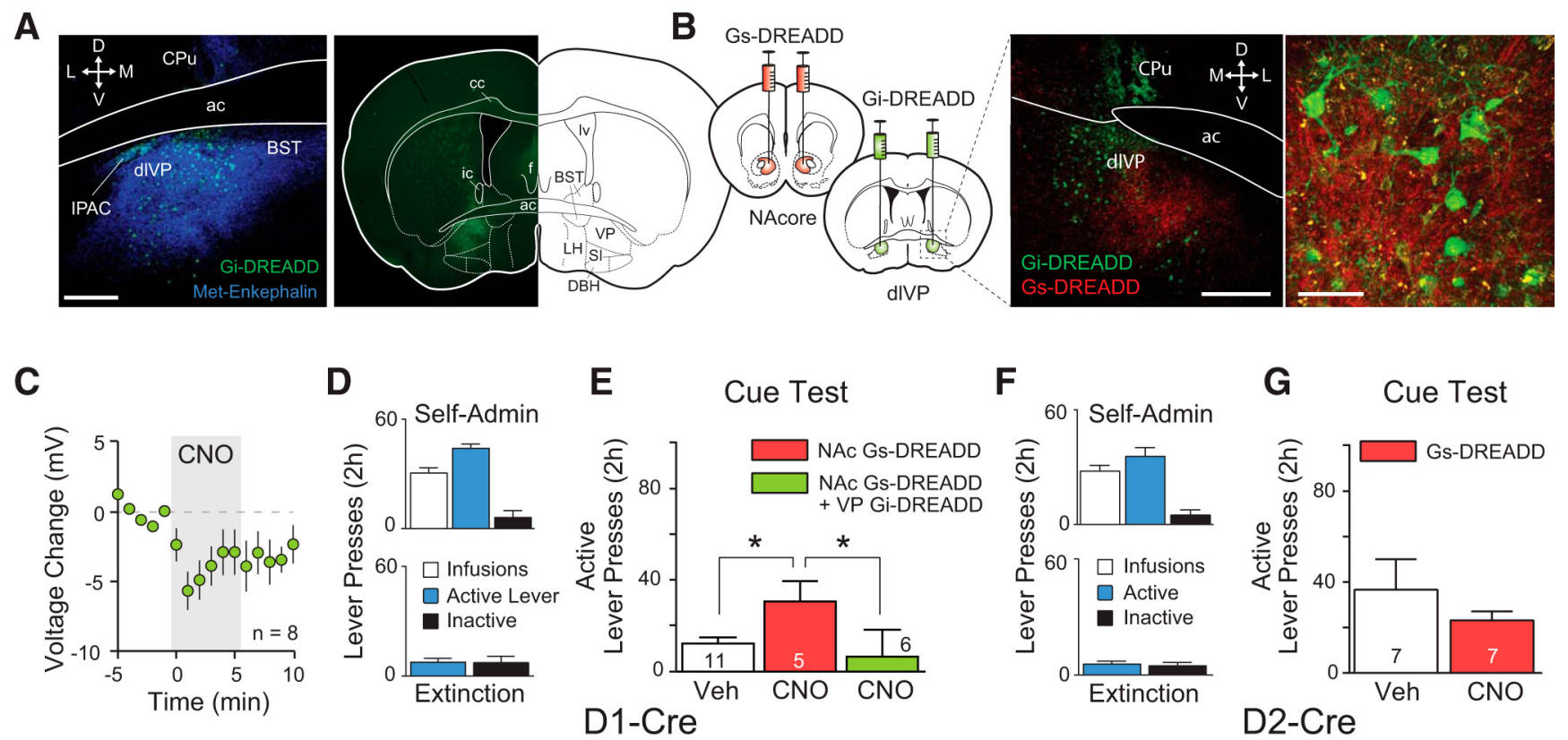

G Cue Test

Figure 3. Augmented cocaine seeking produced by activating D1 MSNs depends on activity in the VP. D1-Cre mice were injected either with Gs-DREADD rM3D in the accumbens core or with a combination of Gs-DREADD in the accumbens core and Gi-DREADD hM4D in the VP.A, Middle, Low-magnification section of Gi DREADD expression in the VP. Left, Higher magnification with colabeled immunostaining for met-enkephalin, a histological marker for the VP. Scale bar, $300 \mu \mathrm{m}$. ac, Anterior commissure; cc, corpus callosum; ic, internal capsule; lv, lateral ventricle; BST, bed nuclei of the stria terminalis; DBH, horizontal nucleus of the diagonal band; LH, lateral hypothalamus; Sl, substantia innominata. Arrows indicate dorsoventral (DV) and mediolateral (ML) orientation. B, Example of accumbens terminals in the dorsolateral VP expressing mCherry (red)-labeled Gs-DREADD surrounded by mCitrine-labeled Gi DREADD (green) infected VP neurons (for coronal example of accumbens core injection site, see Fig. 1B). Scale bars: left, $300 \mu \mathrm{m}$; right, $60 \mu \mathrm{m}$. (Pu, Caudate-putamen; dIVP, dorsolateral part of the VP. C, Bath application of CNO (1 $\mu \mathrm{m}$ ) hyperpolarized VP neurons infected with Gi-DREADD. D. Average active lever, inactive lever presses, and cocaine infusions earned over last $3 \mathrm{~d}$ of self-administration (top) and active and inactive lever pressing over last $2 \mathrm{~d}$ of extinction training (bottom) for D1-Cre mice. E, Stimulation of Gs-DREADD in D1-MSNs augmented cue-induced reinstatement, which was reversed by the simultaneous inhibition of the VP. Numbers in all bars indicate animals. ${ }^{*} p<0.05$, Tukey posthoc test. $F$, Summary of average active lever, inactive lever presses during self-administration, and extinction data for $D 2$-Cre mice infected with Gs-DREADD in accumbens D2-MSNs. G, Stimulating Gs-DREADD in D2-MSNs had no effect on cue-induced reinstatement of cocaine seeking.

There was no difference in lever pressing between the two transgenic mouse strains and both strains distinguished between the active and inactive lever after $3 \mathrm{~d}$ of self-administration (Fig. 1A). Both strains showed a marked extinction burst, evidenced by an increase in active lever pressing during the first extinction session compared with the average last $3 \mathrm{~d}$ of self-administration (Fig. 1A; D1-Cre: $t_{(25)}=3.681, p=0.001$; D2-Cre: $t_{(28)}=4.342, p<$ 0.001). All mice were microinjected with AAV vectors carrying transgenes for the DIO Gs-coupled receptor rM3D (Gs-DREADD; Fig. $1 B$ ), and the DIO or nonfloxed Gi-coupled hM4D receptor (Gi-DREADD; see Figs. $2 A, 3 A, B, 4 B$ ). Alternatively, for electrophysiological studies mice were infected with an AAV carrying a DIO channel rhodopsin (ChR2) (Fig. 2A). Microinjections were targeted to the nucleus accumbens core adjacent to the anterior commissure and showed limited spread into the medial and ventral accumbens shell. Expression of the transgenes was localized to MSNs as indicated by DARPP-32 counterstaining (Fig. 1B) (Bertran-Gonzalez et al., 2008).

To demonstrate the efficacy of these genetic reagents in modulating activity in the accumbens-pallidal pathway, separate groups of drug-naive D1- and D2-Cre mice were infected with a combination of DIO Gi-DREADD and ChR2 vectors. Both constructs expressed robustly in the D1 and D2 projections to the VP (Fig. 2A). Optical stimulation (460 nm) evoked eIPSCs in neurons of the dorsolateral $\mathrm{VP}$, and bath application of the GiDREADD ligand CNO $(1 \mu \mathrm{M})$ abolished these eIPSCs from both D1 and D2 pathway projections onto VP neurons demonstrating significant terminal silencing by Gi-DREADD (Fig. 2B; two-way ANOVA: effect of pathway $F_{(2,12)}=51.48, p<0.001$, drug $F_{(1,12)}=$ 240.7, $p<0.001$, and interaction $\left.F_{(2,12)}=54.09, p<0.001\right)$.

\section{Activating D1-MSNs augmented reinstatement of cocaine seeking via projections to the VP}

Activation of D1-MSNs potentiates the execution of motivated behaviors, whereas activation of D2-MSNs reduces them (Lobo and Nestler, 2011; Smith et al., 2013). Dopamine exerts its effects on D1-MSNs by stimulating the Gs signaling cascade, which enhances the excitability of these neurons when in a relatively depolarized up state, without directly altering membrane potential (Surmeier et al., 2007). In line with this, activation of the GsDREADD does not change the resting membrane potential of infected neurons (Nakajima et al., 2016). The nucleus accumbens of D1-Cre mice was transduced with the DIO Gs-DREADD rM3D and the nonfloxed Gi-DREADD hM4D into the VP to allow simultaneous activation of D1-MSN and inhibition of VP neurons (Fig. $3 A, B$ ). To test the functionality of the GiDREADD in the VP, infected neurons were patched in current clamp while $\mathrm{CNO}(1 \mu \mathrm{M})$ was bath applied to measure changes in membrane potential. CNO significantly hyperpolarized VP neurons infected with the Gi-DREADD (Fig. $3 C ; \Delta \mathrm{V}_{\mathrm{m}}$ mean $\pm \mathrm{SEM}$ : $-4.03 \pm 1.44 ; t_{(7)}=2.80, p=0.027$ comparing min $1-5$ with baseline). Activating D1-MSNs with the Gs-DREADD during cue-induced reinstatement increased cocaine seeking (Fig. 3D,E), and this was reversed by the simultaneous inhibition of VP neurons with Gi-DREADD (one-way ANOVA: $F_{(2,19)}=5.48, p=$ $0.013)$. In contrast, activating D2-MSNs in D2-Cre mice infected with Gs-DREADD using CNO did not reveal any effect during cue-induced reinstatement (Fig. $3 F, G$; $t_{(6)}=0.834, p=0.436$ ). These data demonstrate that activating D1-MSNs is sufficient to potentiate cocaine seeking, most likely via their projections to the VP. 


\section{Inhibiting D2-MSNs augmented reinstatement of cocaine} seeking via projections to the VP

D2-Cre mice were injected with the inhibitory DIO Gi-DREADD targeted to the nucleus accumbens core and trained to selfadminister cocaine. In addition, some D2-Cre mice received a second microinjection with nonfloxed Gi-DREADD in the VP (Fig. 4A, $B$ ). Following cocaine self-administration and extinction, mice underwent a test for cue-induced reinstatement after pretreatment with either vehicle or $\mathrm{CNO}(1 \mathrm{mg} / \mathrm{kg}$, i.p.). Inhibition of D2-MSNs with the Gi-DREADD augmented cue-induced reinstatement (Fig. 4C,D). The augmented cocaine seeking was reversed by simultaneous inhibition of neurons in the VP with the Gi-DREADD (one-way ANOVA: $F_{(2,19)}=15.71 ; p<0.001$ ). In contrast, inhibiting D1-MSNs did not affect cue-induced cocaine seeking $\left(t_{(5)}=1.106, p=0.319\right.$; Fig. $\left.4 E, F\right)$. These data show that inhibiting D2-MSNs potentiates reinstatement, which depends on the D2 projection to the VP.

\section{Activating D1-MSNs did not alter reinstatement of sucrose seeking}

In addition to its critical role in drug seeking, the accumbens core is also involved in food seeking behavior (Peters and Kalivas, 2006; Floresco et al., 2008), and sucrose consumption (Francis et al., 2015). These studies suggest that the bidirectional effect of D1- versus D2-MSNs extends to non-drug-related motivated behaviors. We explored the generalizability of our findings to food reward by chemogenetically activating D1- and D2-MSNs transfected with the DIO Gs-DREADD during the reinstatement of sucrose seeking. Following sucrose self-administration and extinction, in a manner analogous to that of cocaine (Fig. 5A,C), mice were pretreated with $\mathrm{CNO}$ or vehicle, and tested for cueinduced reinstatement of sucrose seeking. In contrast with cocaine-seeking, no effects of $\mathrm{CNO}$ were observed in either D1-Cre mice (Fig. $5 B ; t_{(10)}=0.58, p=0.572$ ) or D2-Cre mice (Fig. $5 D ; t_{(10)}=0.250, p=0.811$ ). This was surprising given the studies showing that selective D1-MSN stimulation reinforces behavior (Lobo et al., 2010; Ferguson et al., 2011; Kravitz et al., 2012), and indicates that while the cue-cocaine association can be regulated by accumbens D1- and D2-MSNs, the cue-sucrose association might be independent of the accumbens. One possibility is that previous studies showing a role for the accumbens used food, not food-paired conditioned cues to motivate animals. To explore the possibility that food availability is critical, D1-Cre mice infected with DIO Gs-DREADD were re-extinguished for at least $2 \mathrm{~d}$ after the cue-induced reinstatement session and tested for reinstatement elicited by both cues and noncontingent sucrose delivery. Under these conditions, a marked potentiation of reinstatement by $\mathrm{CNO}$ was evident (Fig. $5 B$; $t_{(9)}=3.352, p=$ 0.009). In D2-Cre mice infected with DIO Gs-DREADD, CNO did not potentiate reinstatement induced by both cues and sucrose pellets (Fig. $5 D ; t_{(6)}=0.721, p=0.498$ ).

\section{Cocaine self-administration selectively altered synaptic plasticity in the D2 pathway while sparing plasticity in the D1 pathway to the VP}

Both D1- and D2-MSN projections from the nucleus accumbens core robustly innervate the VP ( $\mathrm{Lu}$ et al., 1998; Francis et al., 2015), and at least 50\% of dorsolateral VP neurons are innervated by both MSNs (Kupchik et al., 2015). Because activity in VP neurons was necessary for the chemogenetic regulation of cocaine seeking in both D1- and D2-Cre mice, we next investigated how parallel innervation of the VP by distinct D1- and D2-MSNs could contribute to cocaine seeking. We postulated that cocaine self-administration might differentially alter GABAergic synaptic transmission in these pathways in a manner that facilitates reinstated behavior. To evaluate the synaptic physiology of the D1 and D2 pathways to the VP, D1- and D2-Cre mice received microinjections into the nucleus accumbens core with an AAV the DIO ChR2 transgene (Kupchik et al., 2015), resulting in the labeling of ChR2-expressing terminals in the VP (Fig. 2A). Following cocaine self-administration and extinction, whole-cell patch recordings were obtained from dorsolateral VP neurons, and GABAergic eIPSCs were evoked by application of blue light pulses (0.5-1 ms duration) (Fig. 6A,B). Using an electrical HFS protocol previously shown to induce $\mathrm{LTD}_{\mathrm{GABA}}$ in the accumbenspallidal pathway in rats (Kupchik et al., 2014), we induced $\mathrm{LTD}_{\mathrm{GABA}}$ in synapses from both the D1 and D2 pathway onto VP neurons of yoked saline (D1: $n=7 ; \mathrm{D} 2: n=8)$ and drug-naive (D1: $n=2 ;$ D2: $n=1$ ) mice. No differences were observed between these two groups; data were thus pooled for analyses. The HFS protocol induced $\mathrm{LTD}_{\mathrm{GABA}}$ (Fig. 6C; two-way ANOVA: effect of time $\left.F_{(19,304)}=2.97, p<0.001\right)$, and no differences were observed between $\mathrm{LTD}_{\mathrm{GABA}}$ in D1 and D2 pathway eIPSCs. Comparing baseline to the average eIPSC over 6-15 min after inducing $\mathrm{LTD}_{\mathrm{GABA}}$ revealed significant LTD in both D1 $t_{(8)}=2.82, p=$ 0.023 ) and $D 2$ pathways (Fig. $6 D ; t_{(8)}=3.47, p=0.008$ ). By contrast, in VP neurons from cocaine self-administering and extinguished mice, HFS failed to induce $\mathrm{LTD}_{\mathrm{GABA}}$ in the $\mathrm{D} 2$ pathway (Fig. $6 \mathrm{~F}$; two-way ANOVA: effect of pathway $F_{(1,11)}=12.83, p=0.004$, and interaction $F_{(19,209)}=2.925, p<0.001$, but no effect of time). Average post-HFS eIPSC amplitude compared with baseline revealed that this effect was specific to the D2 pathway (Fig. 6G; $\left.t_{(5)}=3.81, p=0.013\right)$, whereas $\mathrm{LTD}_{\mathrm{GABA}}$ in the $\mathrm{D} 1$ pathway remained intact $\left(t_{(6)}=1.54, p=0.176\right)$.

We next assessed the paired pulse ratio (PPR) after LT$\mathrm{D}_{\mathrm{GABA}}$ induction to assess whether this $\mathrm{LTD}_{\mathrm{GABA}}$ was presynaptic. The PPR was increased for both D1 and D2 pathways in control mice (Fig. $6 E ; t_{(7)}=2.65, p=0.033$ and $t_{(8)}=5.11$, $p<0.001$ for D1 and D2 pathway terminals, respectively). Similarly, in cocaine-extinguished mice, the PPR was increased after inducing $\mathrm{LTD}_{\mathrm{GABA}}$ in D1-MSNs (Fig. $6 H ; t_{(3)}=$ $3.14, p=0.025)$. However, the failure to induce $\mathrm{LTD}_{\mathrm{GABA}}$ in $\mathrm{D} 2$ pathway afferents of cocaine-extinguished mice was associated with no change in the PPR (Fig. $6 H ; t_{(6)}=1.29, p=0.245$ ). Together, these PPR data indicate that the ability to induce LT$\mathrm{D}_{\mathrm{GABA}}$ is likely due to a decrease in presynaptic transmitter release probability (Bonci and Williams, 1997).

\section{Persistent activation of MOR accounts for the loss of LTD in the $\mathrm{D} 2$ pathway to the VP}

Enkephalin is colocalized with GABA in D2-, but not D1expressing, MSNs (Zahm et al., 1985; Lu et al., 1998) and modulates neurotransmission in the accumbens-pallidal pathway (Chrobak and Napier, 1993). These effects are likely mediated by presynaptic MOR located on MSN terminals within the VP (Olive et al., 1997; Kupchik et al., 2014). Consistent with recent findings that GABAergic synapses in the VP undergo a MORdependent LTD after the electrically stimulated release of enkephalin (Kupchik et al., 2014), LTD $_{\text {GABA }}$ was blocked in both D1 and D2 pathways to the VP of cocaine-naive mice by bath application of the MOR antagonist CTOP (50 nM) (Fig. 7 A, B; twoway ANOVA: no effect of pathway, time, or interaction). Recordings from both yoked saline (D1: $n=6$, D2: $n=3$ ) and naive mice (D1: $n=3$, D2: $n=3$ ) were pooled for this analysis because no differences in eIPSCs were observed. Thus, the loss of $\mathrm{LTD}_{\mathrm{GABA}}$ in the $\mathrm{D} 2$ pathway may result from a persistent increase 
A

B
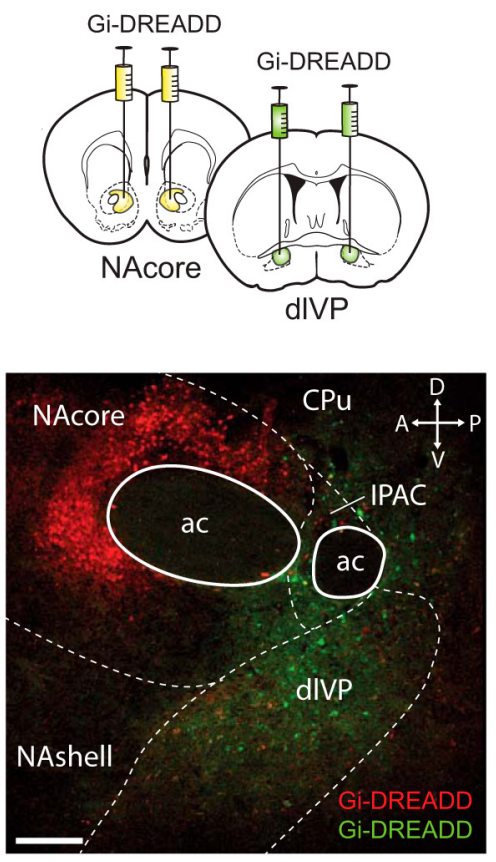

C
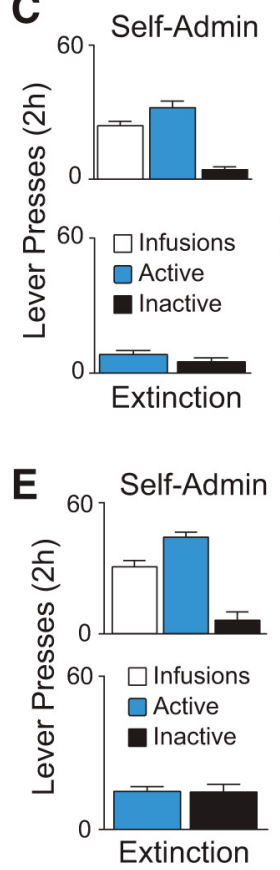

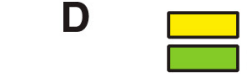

NAc Gi-DREADD

NAc Gi-DREADD +VP Gi-DREADD

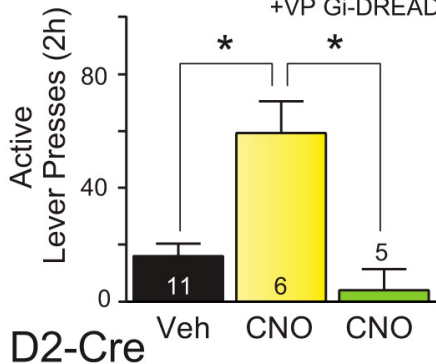

$\mathbf{F}$

Cue Test

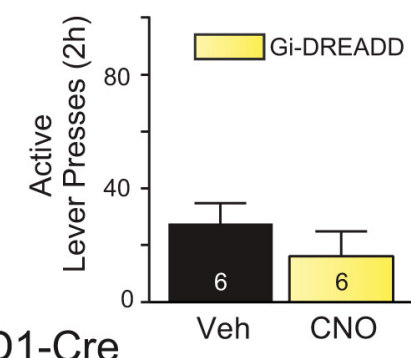

Figure 4. Augmented cocaine seeking produced by inhibiting D2 MSNs depends on activity in the VP. $A, D 1$ - and D2-Cre mice were infected with Gi-DREADD hM4D in the accumbens alone or a combination of Gi-DREADD in the accumbens and Gi-DREADD in the VP. B, Sagittal image showing coexpression of mCherry-labeled Gi-DREADD-expressing neurons in the accumbens core (NAcore, red) and mCitrine-labeled Gi-DREADD-expressing neurons in the VP (green). Scale bar, $200 \mu \mathrm{m}$. IPAC, Interstitial nuclei of the posterior limb of the anterior commissure; CPu, caudate-putamen; dIVP, dorsolateral part of the VP. NAshell, nucleus accumbens shell. Arrows indicate anteroposterior (AP) and dorsoventral (DV) orientation. C, Average responding on the active lever and inactive lever, as well as infusions earned over the last $3 \mathrm{~d}$ of self-administration and $2 \mathrm{~d}$ of extinction in D2-Cre mice infected with Gi-DREADD in the accumbens and dorsolateral VP. D, Accumbens D2-MSN inhibition augmented cue-induced reinstatement, which was reversed by the simultaneous inhibition of the VP. Numbers in all bars indicate animals. ${ }^{*} p<0.001$, Tukey post hoc. $E$, Average active lever and inactive lever presses and infusions during the last $3 \mathrm{~d}$ of self-administration and $2 \mathrm{~d}$ of extinction for D1-Cre mice transduced with Gi-DREADD in the accumbens. $\boldsymbol{F}$, Inhibition of accumbens D1-MSN had no effect on cue-induced reinstatement of cocaine seeking. Numbers in all bars indicate animals.
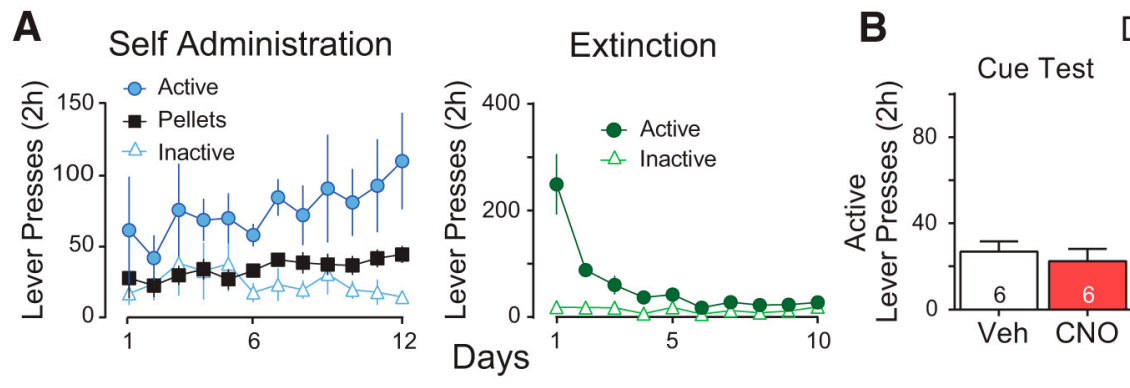

D1-Cre
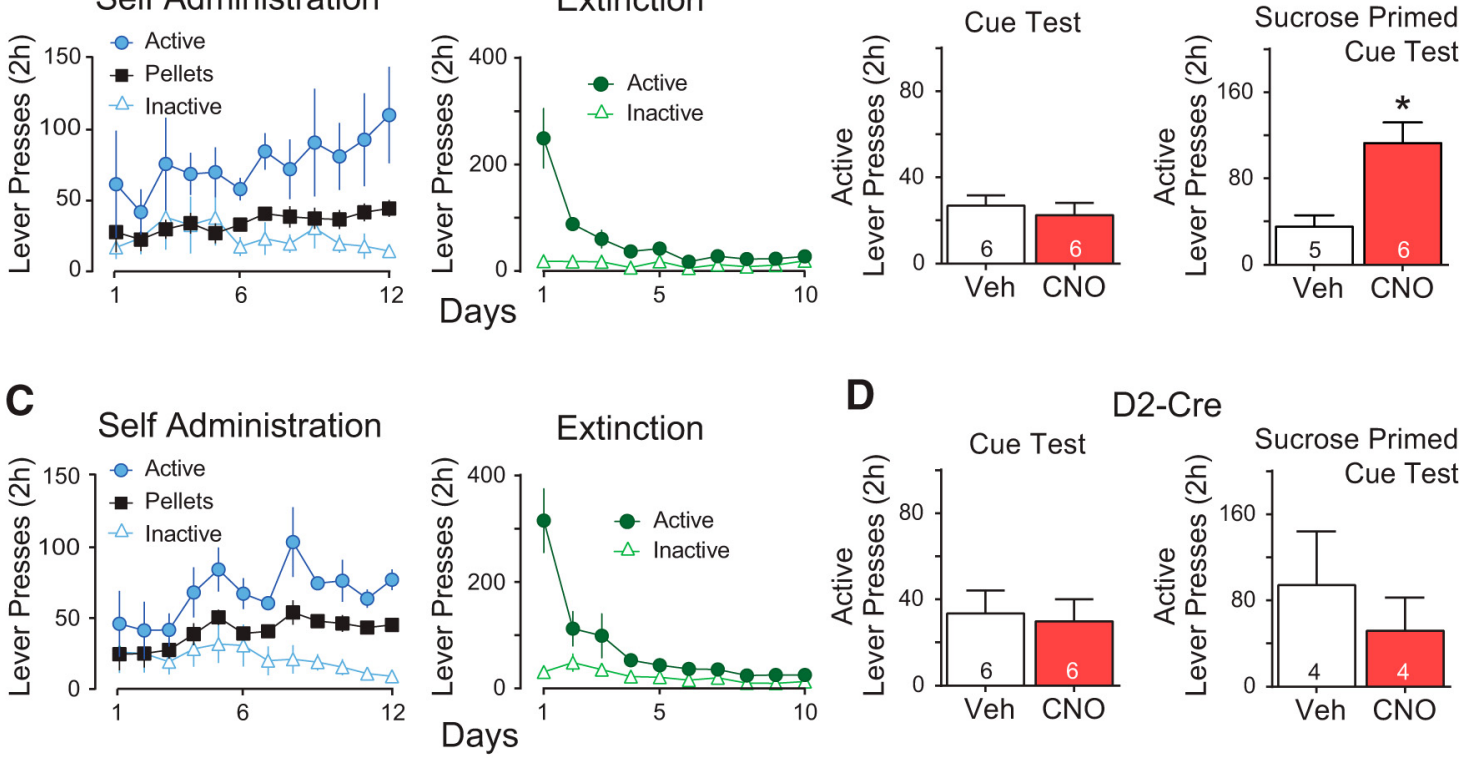

Figure 5. Stimulation of D1-MSNs did not affect cue-induced sucrose seeking but increased responding in the presence of both cues and noncontingent sucrose pellets. $A$, Self-administration and extinction of sucrose in D1-Cre mice $(n=6)$. B, Stimulation of Gs-DREADD rM3D in accumbens D1-MSNs with CN0 did not affect cue-induced reinstatement of sucrose seeking but significantly increased reinstatement to both cues and noncontingently delivered sucrose pellets. ${ }^{*} p<0.05$, vehicle compared with CNO ( $t$ test). Bars represent number of mice. $C$, Sucrose self-administration and extinction in D2-Cre mice $(n=6)$. D, Stimulation of Gs-DREADD in D2-MSNs did not affect cue-induced reinstatement of sucrose seeking in the presence or absence of noncontingent sucrose pellets. Bars represent number of mice tested. 

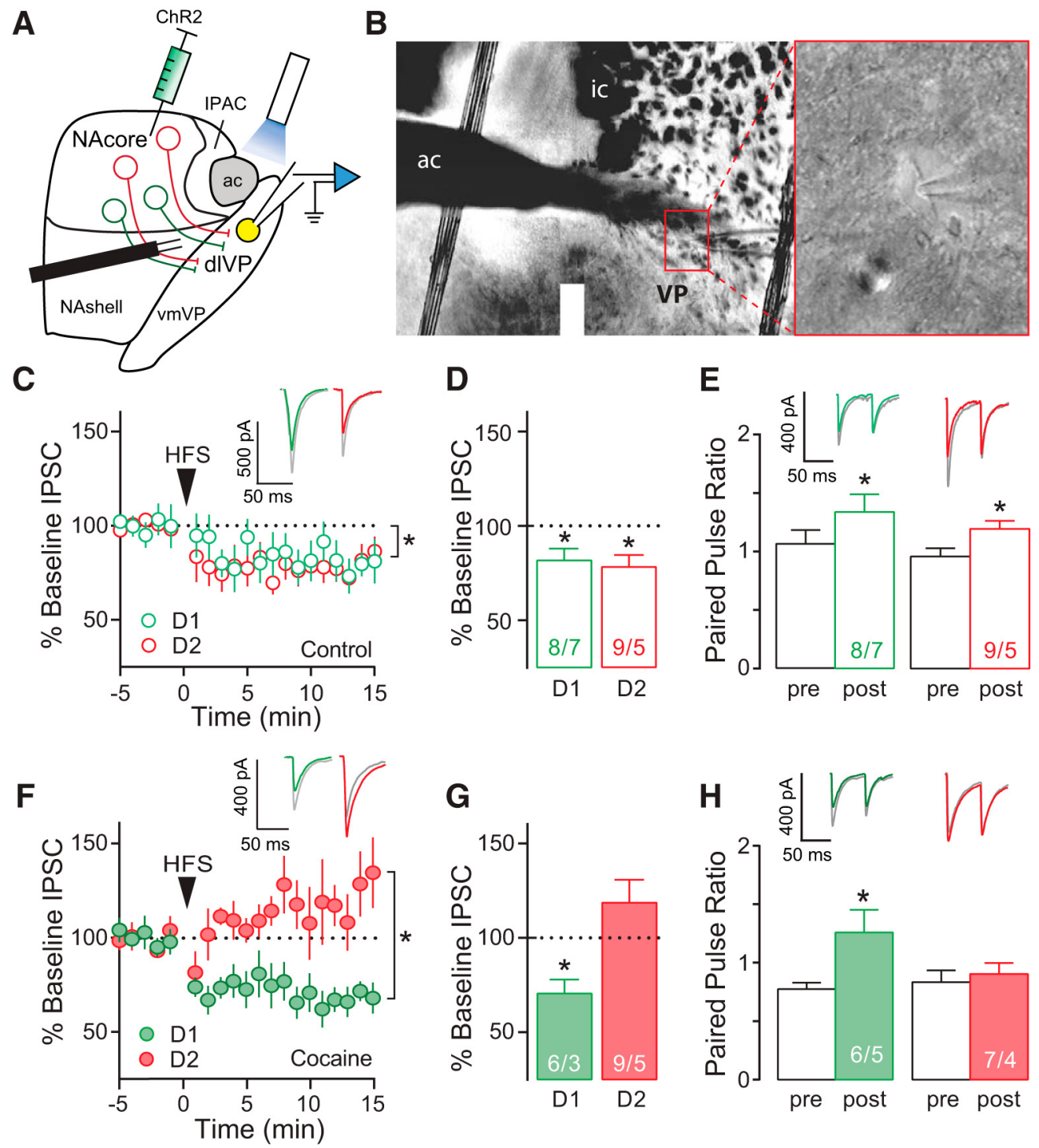

Figure 6. Induction of $\mathrm{LTD}_{\mathrm{GABA}}$ was selectively abolished in accumbens-pallidal synapses of the dorsolateral VP after cocaine self-administration. $\boldsymbol{A}$, Experimental setup for slice electrophysiology experiments illustrated on a sagittal section. Channelrhodopsin injected in the accumbens of D1-Cre or D2-Cre mice was used for eliciting optical elPSCs in VP neurons. Following baseline recordings, HFS was applied by electrically stimulating the accumbens-pallidal pathway in current clamp, after which optically evoked IPSCs were recorded from dorsolateral VP neurons. IPAC, Interstitial nuclei of the posterior limb of the anterior commissure; ac, anterior commissure; dIVP, dorsolateral part of the VP; vmVP, ventromedial part of the VP. B, Location of recordings in subcommissural dorsolateral VP and example of a patched VP neuron (insert right). ic, Internal capsule. C, Time course of optically evoked elPSCs recorded from VP neurons induced by the selective optical stimulation of D1 and D2 terminals in yoked saline and naive mice before and after electrical HFS. Inserts (above graph), Example traces of optically evoked current traces before (gray) and after (colored) electrical HFS. ${ }^{*} p<0.001$, main effect of time. $\boldsymbol{D}$, Boxplots for averaged normalized elPSC responses. ${ }^{*} p<0.05, t$ test comparing baseline (100\%) with the average of $6-15$ min after HFS in control mice. $\boldsymbol{E}$, HFS increased PPR compared with baseline. Traces represent optical elPSCs recorded from VP neurons before and after HFS. ${ }^{*} p<0.05, t$ test comparing prestimulation with poststimulation. $\boldsymbol{F}$, Time course of optically evoked elPSCs before and after HFS from cocaine self-administering mice. ${ }^{*} p<0.001$, interaction D1 and D2 projection and time. G, Cocaine self-administration and extinction abolished HFS-induced LTD ${ }_{\text {GABA }}$ in D2 pathway synapses. ${ }^{*} p<0.05$, $t$ test comparing baseline to the average $6-15$ min after HFS. $\boldsymbol{H}$, Cocaine self-administration had no effect on the increase in PPR in the D1 pathway, but abolished this increase in the D2 pathway to the VP. ${ }^{*} p<0.05, t$ test comparing prestimulus with poststimulus. Numbers in all bars indicate cells/animals.

in MOR tone that effectively masks MOR-induced LTD in cocaine-extinguished mice. Consistent with this, bath applied CTOP had no effect on the amplitude of D1 or D2 pathway eIPSCs in the dorsolateral VP of control mice (Fig. 7C,D; twoway ANOVA: no effect of pathway, time, or interaction), but it selectively increased the amplitude of D2 pathway, but not D1 pathway eIPSCs in cocaine-extinguished mice (Fig. 7E; two-way ANOVA: effect of treatment $F_{(1,19)}=8.276, p<0.01$ and interaction $F_{(20,380)}=2.56, p<0.001$, but no effect of time). Comparing baseline to the average of min 6-15 during CTOP application showed an increase in eIPSC amplitude selectively in
D2 pathway terminals (Fig. $7 F ; t_{(11)}=3.076, p=0.011$ ), but not in D1 pathway terminals $\left(t_{(8)}=0.918, p=0.385\right)$. These results suggest that MORs are tonically activated on D2, but not D1, pathway terminals in the VP of cocaine-extinguished mice.

\section{Discussion}

In mice extinguished from cocaine self-administration, chemogenetic activation of D1-MSNs or inhibition of D2-MSNs in the nucleus accumbens core increased cue-induced reinstatement of cocaine seeking. Regardless of which MSN cell type was chemogenetically regulated to augment cued reinstatement, output to the 

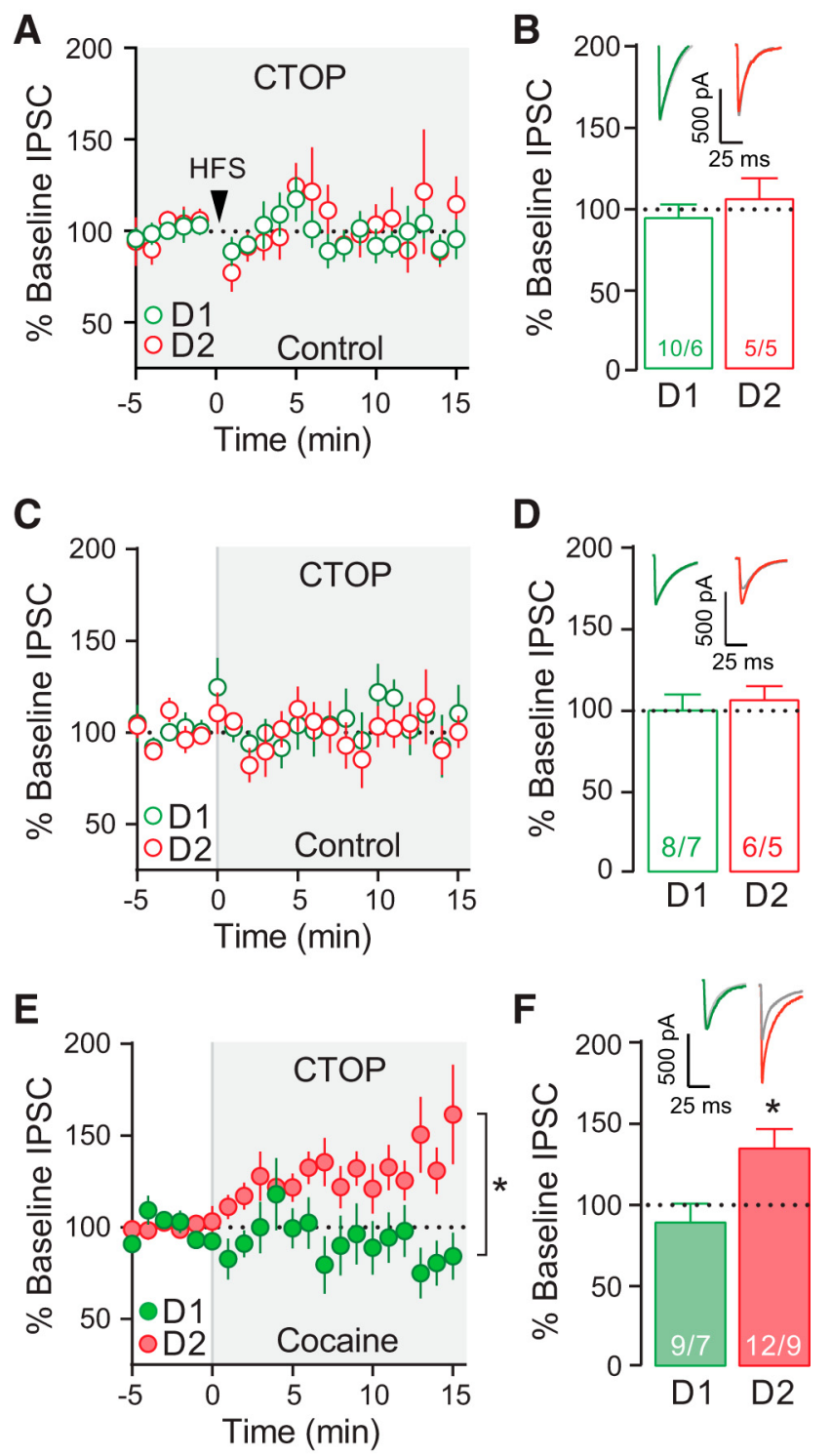

Figure 7. Constitutive tone onto MORs after cocaine exposure in D2 pathway synapses masks $\mathrm{LTD}_{\mathrm{GABA}} \cdot A$, Bath application of the selective MOR antagonist CTOP blocked HFS-induced $\mathrm{LTD}_{\mathrm{GABA}}$ in both D1 and D2 pathway synapses. Gray background fill represents application of CTOP. Arrowhead indicates application of the electrical HFS protocol. $\boldsymbol{B}$, Summary of optically evoked IPSCS after HFS from control mice. CTOP blocked $\mathrm{LTD}_{\mathrm{GABA}}$ in both the D1 and D2 pathway to the VP. Dashed line indicates baseline recordings averaging 100\%. Traces represent typical elPSC before (gray) and after (colored) LTD protocol application. C, Bath application of CTOP had no effect on brain slices from control mice in the D1 pathway or the D2 pathway to the VP, indicating no endogenous MOR tone. $\boldsymbol{D}$, CTOP did not affect eIPSCs in D1 or D2 pathway synapses of control mice. Gray line and fill indicates the start of CTOP application. Traces represent typical eIPSCs before (gray) and after (colored) CTOP application. $\boldsymbol{E}$, CTOP application restored elPSC amplitude in the D2 pathway by unmasking MOR tone in the VP, without affecting eIPSC amplitude in the D1 pathway to the VP. Gray line and fill indicate the start of CTOP application. ${ }^{*} p<0.001$, interaction between D1 and D2 pathway and time. $\boldsymbol{F}$, Bar graphs summarizing change in eIPSC after CTOP application. ${ }^{*} p<0.05, t$ test comparing baseline to the average of $\min 6-15$ during CTOP application. Traces represent typical elPSC 5 before (gray) and after (colored) CTOP application. Numbers in all bars represent cells/animals.

VP was required because simultaneous inhibition of VP neurons prevented reinstatement. We hypothesized that GABAergic transmission and plasticity in one or both of these pathways to the VP would be altered by cocaine self-administration. Indeed, the ability to induce $\mathrm{LTD}_{\mathrm{GABA}}$ in dorsolateral VP neurons was abolished in the $\mathrm{D} 2$ pathway after cocaine, whereas $\mathrm{LTD}_{\mathrm{GABA}}$ was spared at D1 synapses. $\mathrm{LTD}_{\mathrm{GABA}}$ in both accumbens-pallidal projections was presynaptic and depended on MORs because

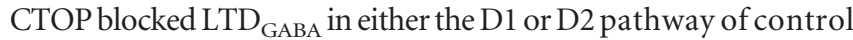
mice. However, cocaine use masked this plasticity by increasing endogenous MOR tone specifically on D2-MSN terminals because CTOP restored GABAergic currents in this pathway. These data indicate that D1- and D2-MSNs bidirectionally regulate cocaine seeking through projections to the VP, and that increased MOR tone decreases D2 pathway GABA transmission in the VP, thus shifting the inherent balance of the circuit in favor of the D1 pathway to facilitate cocaine seeking.

\section{Differential roles for D1- and D2-MSNs in relapse to drug seeking}

Multiple studies reveal opposing roles for D1- and D2-MSNs in cocaine-related behavior (Lobo et al., 2010; Bock et al., 2013; Pascoli et al., 2014). For instance, D2-MSNs display reduced activity during expression of a cocaine conditioned place preference, whereas D1-MSN activity increases immediately before entry into a cocaine-paired compartment (Calipari et al., 2016). In line with these studies, we found that activating D1-MSNs increased cue-induced cocaine seeking. In addition to the dorsolateral VP, accumbens core D1-MSNs project to substantia nigra, and neither pharmacological nor optogenetic silencing of this D1 pathway affected on cocaine seeking (McFarland and Kalivas, 2001; Stefanik et al., 2013). Although systemic activation of DREADDs in multiple brain regions is not conclusive evidence of a monosynaptic pathway between D1-MSNs or D2-MSNs and the VP in driving drug seeking, it shows that the VP is a critical downstream mediator.

Our finding that inhibiting D2-MSNs also increased drug seeking in a VP-dependent manner is consistent with a previous study showing that synaptic strength onto D2-MSNs is inversely correlated with cocaine use and inhibiting D2-MSNs increases the motivation to take cocaine (Bock et al., 2013). Thus, D2MSNs suppress cocaine seeking, and reducing activity of these cells predisposes animals to increase responding for drugs and drug-associated cues. D2-MSNs also evaluate proper response strategies (Zalocusky et al., 2016) and guide flexible behavior (Yawata et al., 2012). Thus, inhibiting their activity may render animals less prone to change their response strategy despite changes in reward contingencies.

Chemogenetic activation of Gs-coupled signaling in D1MSNs and Gi-signaling on D2-MSNs mimics the effects of dopamine onto these neurons. Dopamine is released into accumbens core during conditioned cue presentation in abstinent cocaine self-administering animals (Phillips et al., 2003) and is necessary for cue-induced cocaine seeking in sign-tracking animals (Saunders et al., 2013). Although systemic D2 receptor agonists and intra-accumbens shell microinjections of D1 or D2 receptor agonists reinstates cocaine seeking (Self et al., 1996; De Vries et al., 2002; Schmidt et al., 2006), microinjecting a D1/D2-receptor antagonist or selective D1/D2-receptor agonists into the accumbens core does not reduce or increase, respectively, reinstated cocaine seeking (McFarland and Kalivas, 2001; Schmidt et al., 2006). Thus, dopamine likely facilitates reinstatement only in conjunction with circuit activity in glutamatergic accumbens core afferents, as evidenced by D1 receptor signaling facilitating MSN activity only when the cells are in a depolarized state (Surmeier et al., 2007).

Opposing cocaine-induced adaptations in D1- and D2-MSNs Confirming previous studies, we demonstrated that cocaine changes MOR regulation of GABAergic transmission in the VP 
(Tang et al., 2005; Kupchik et al., 2014). Although only D2-MSNs release enkephalin in the VP, both D1 and D2 synapses demonstrated MOR-dependent $\mathrm{LTD}_{\mathrm{GABA}}$ in control mice. This may be caused by the spillover of enkephalin from D2-MSN terminals after the HFS protocol used to induce $\mathrm{LTD}_{\mathrm{GABA}}$, thus reflecting heterosynaptic plasticity. However, enkephalin exerts greater tonic presynaptic inhibition on D2-MSN terminals after cocaine use because CTOP only increased eIPSC amplitude in D2, not D1, pathway synapses. Thus, homosynaptic tonic stimulation of presynaptic MORs on D2-MSN terminals occurs in the VP after cocaine use, and this occludes LTD selectively in D2-MSN synapses. These findings demonstrate cell-type specificity of MOR plasticity in the accumbens-pallidal pathway and add to a growing literature on MOR-dependent LTD in various neural systems (Wamsteeker Cusulin et al., 2013; Atwood et al., 2014).

A recent study found that repeated cocaine injections change plasticity in both D1- and D2-MSN projections to the ventromedial VP (Creed et al., 2016). Although a similar loss of LTD in the D2 pathway was observed, a striking loss of LTP was found for the D1 projection. This bidirectional loss of plasticity in the D1 and D2 pathways was associated with cocaine-induced sensitization and withdrawal-induced anhedonia, respectively. Moreover, D2 pathway plasticity was mediated by presynaptic $\delta$ opioid receptors. The distinctions between our studies may arise because we electrically stimulated the entire projection to induce plasticity and then optogenetically interrogated the circuit for D1- and D2-MSN involvement, whereas Creed et al. (2016) both induced plasticity and interrogated the circuit selectively stimulating D1and D2-MSN afferents. Also, our studies examined two distinct subcircuits. Although only $\sim 50 \%$ of dorsolateral VP neurons are functionally innervated by D1-MSNs (Kupchik et al., 2015), apparently nearly all ventromedial VP neurons receive D1-MSN innervation from accumbens shell (Creed et al., 2016). Also, although Creed et al. (2016) focused exclusively on ventromedial VP neurons projecting to the VTA, our recordings did not discriminate among dorsolateral VP neurons, and the different topographies of the dorsolateral and ventromedial VP efferent projections indicate the two studies recorded from largely nonoverlapping circuits (Zahm, 1989; Bell et al., 1995).

Collectively, these findings indicate that cocaine use reorganizes the balance between D1- and D2-MSN inputs to VP by enhancing enkephalin tone on D2 pathway synapses. The shift in balance of accumbens-pallidal output in favor of the D1 pathway is parsimonious with electrophysiological studies showing overall strengthened glutamatergic inputs onto accumbens D1-MSNs after contingent (Bock et al., 2013; Pascoli et al., 2014) and noncontingent cocaine or heroin exposure (Pascoli et al., 2011; MacAskill et al., 2014; Hearing et al., 2016), as well as increased expression of genes involved in synaptic plasticity (e.g., Egr3 and $\triangle$ FosB) in D1-MSNs and decreased expression in D2-MSNs (Grueter et al., 2013; Lobo et al., 2013; Chandra et al., 2015).

\section{How can D1 and D2 MSN afferents in the VP produce bidirectional behavior?}

Given that the D1 and D2 pathways are GABAergic and synapse on substantially overlapping VP neurons (Kupchik et al., 2015), possibly even targeting the same dendritic segment (Pickel et al., 2012), it is surprising that opposite behaviors are engendered by the two MSN populations. This indicates a level of nuanced regulation beyond simple inhibition of VP neurons by GABA released from MSNs. How both D1 and D2 pathway GABAergic synapses in the VP encode opposite behaviors is unknown, but different neuropeptides coreleased with GABA in D1- versus D2-MSN terminals are likely candidates in the differential encoding of information between these pathways. For instance, enkephalin from D2 pathway terminals inhibits the presynaptic release of GABA into the VP (Kupchik et al., 2014), and thereby disinhibits VP neurons to augment cocaine reinstatement (Tang et al., 2005). Thus, blocking MORs in the VP inhibits reinstatement of cocaine and alcohol seeking (Tang et al., 2005; Perry and McNally, 2013). MOR signaling in the VP also mediates hedonic responses (Smith and Berridge, 2005), which may contribute to drug seeking.

Another mechanism by which D1- and D2-MSN inputs to the VP could elicit opposite effects on cocaine seeking is through targeting VP neurons that project to different downstream areas, such as the medial thalamus and ventral mesencephalon (Haber et al., 1985; Groenewegen et al., 1993; Tripathi et al., 2013). However, dorsolateral VP neurons retrogradely labeled from these two major output structures did not respond differently to D1- and D2-MSN input (Kupchik et al., 2015).

A final possibility is that D1 and D2 pathways project to different neuronal subtypes in the VP. A proportion of VP cells are glutamatergic, which could drive opposite downstream effects from those elicited by GABAergic neurons. For example, the projection from ventromedial VP to the ventral tegmental area contains both GABAergic and glutamatergic efferents and is critical for cocaine seeking (Geisler et al., 2007; Mahler et al., 2014). Thus, the heterogeneous firing patterns observed in VP neurons during cocaine seeking may arise from heterogeneity in neuronal subtypes and subpopulations (Root et al., 2013).

In conclusion, our results demonstrate of a functional role for D1- and D2-MSN projections from the nucleus accumbens to the VP in cue-induced reinstatement of cocaine seeking, and show a differential loss of synaptic plasticity in D2 versus D1 pathways to the VP after cocaine self-administration. These data set the stage for future studies addressing the cell type-specific circuitry of the $\mathrm{D} 1$ and $\mathrm{D} 2$ pathways to the VP in the regulation of drug seeking.

\section{References}

Armbruster BN, Li X, Pausch MH, Herlitze S, Roth BL (2007) Evolving the lock to fit the key to create a family of $\mathrm{G}$ protein-coupled receptors potently activated by an inert ligand. Proc Natl Acad Sci U S A 104:51635168. CrossRef Medline

Atwood BK, Kupferschmidt DA, Lovinger DM (2014) Opioids induce dissociable forms of long-term depression of excitatory inputs to the dorsal striatum. Nat Neurosci 17:540-548. CrossRef Medline

Bell K, Churchill L, Kalivas PW (1995) GABAergic projection from the ventral pallidum and globus pallidus to the subthalamic nucleus. Synapse 20:10-18. CrossRef Medline

Bertran-Gonzalez J, Bosch C, Maroteaux M, Matamales M, Hervé D, Valjent E, Girault JA (2008) Opposing patterns of signaling activation in dopamine D1 and D2 receptor-expressing striatal neurons in response to cocaine and haloperidol. J Neurosci 28:5671-5685. CrossRef Medline

Bock R, Shin JH, Kaplan AR, Dobi A, Markey E, Kramer PF, Gremel CM, Christensen CH, Adrover MF, Alvarez VA (2013) Strengthening the accumbal indirect pathway promotes resilience to compulsive cocaine use. Nat Neurosci 16:632-638. CrossRef Medline

Bonci A, Williams JT (1997) Increased probability of GABA release during withdrawal from morphine. J Neurosci 17:796-803. Medline

Britt JP, Bonci A (2013) Optogenetic interrogations of the neural circuits underlying addiction. Curr Opin Neurobiol 23:539-545. CrossRef Medline

Calipari ES, Bagot RC, Purushothaman I, Davidson TJ, Yorgason JT, Peña CJ, Walker DM, Pirpinias ST, Guise KG, Ramakrishnan C, Deisseroth K, Nestler EJ (2016) In vivo imaging identifies temporal signature of D1 and D2 medium spiny neurons in cocaine reward. Proc Natl Acad Sci U S A 113:2726-2731. CrossRef Medline

Chandra R, Francis TC, Konkalmatt P, Amgalan A, Gancarz AM, Dietz DM, Lobo MK (2015) Opposing role for Egr3 in nucleus accumbens cell subtypes in cocaine action. J Neurosci 35:7927-7937. CrossRef Medline 
Chrobak JJ, Napier TC (1993) Opioid and GABA modulation of accumbens-evoked ventral pallidal activity. J Neural Transm Gen Sect 93:123-143. CrossRef Medline

Creed M, Ntamati NR, Chandra R, Lobo MK, Lüscher C (2016) Convergence of reinforcing and anhedonic cocaine effects in the ventral pallidum. Neuron 92:214-226. CrossRef Medline

De Vries TJ, Schoffelmeer AN, Binnekade R, Raasø H, Vanderschuren LJ (2002) Relapse to cocaine- and heroin-seeking behavior mediated by dopamine D2 receptors is time-dependent and associated with behavioral sensitization. Neuropsychopharmacology 26:18-26. CrossRef Medline

Farrell MS, Pei Y, Wan Y, Yadav PN, Daigle TL, Urban DJ, Lee HM, Sciaky N, Simmons A, Nonneman RJ, Huang XP, Hufeisen SJ, Guettier JM, Moy SS, Wess J, Caron MG, Calakos N, Roth BL (2013) A Galphas DREADD mouse for selective modulation of cAMP production in striatopallidal neurons. Neuropsychopharmacology 38:854-862. CrossRef Medline

Ferguson SM, Eskenazi D, Ishikawa M, Wanat MJ, Phillips PE, Dong Y, Roth BL, Neumaier JF (2011) Transient neuronal inhibition reveals opposing roles of indirect and direct pathways in sensitization. Nat Neurosci 14:2224. CrossRef Medline

Floresco SB (2015) The nucleus accumbens: an interface between cognition, emotion, and action. Annu Rev Psychol 66:25-52. CrossRef Medline

Floresco SB, McLaughlin RJ, Haluk DM (2008) Opposing roles for the nucleus accumbens core and shell in cue-induced reinstatement of foodseeking behavior. Neuroscience 154:877-884. CrossRef Medline

Francis TC, Chandra R, Friend DM, Finkel E, Dayrit G, Miranda J, Brooks JM, Iñiguez SD, O’Donnell P, Kravitz A, Lobo MK (2015) Nucleus accumbens medium spiny neuron subtypes mediate depression-related outcomes to social defeat stress. Biol Psychiatry 77:212-222. CrossRef Medline

Fuchs RA, See RE, Middaugh LD (2003) Conditioned stimulus-induced reinstatement of extinguished cocaine seeking in C57BL/6 mice: a mouse model of drug relapse. Brain Res 973:99-106. CrossRef Medline

Geisler S, Derst C, Veh RW, Zahm DS (2007) Glutamatergic afferents of the ventral tegmental area in the rat. J Neurosci 27:5730-5743. CrossRef Medline

Gerfen CR, Surmeier DJ (2011) Modulation of striatal projection systems by dopamine. Annu Rev Neurosci 34:441-466. CrossRef Medline

Goto A, Nakahara I, Yamaguchi T, Kamioka Y, Sumiyama K, Matsuda M, Nakanishi S, Funabiki K (2015) Circuit-dependent striatal PKA and ERK signaling underlies rapid behavioral shift in mating reaction of male mice. Proc Natl Acad Sci U S A 112:6718-6723. CrossRef Medline

Griffin WC 3rd, Middaugh LD (2003) Acquisition of lever pressing for cocaine in C57BL/6J mice: effects of prior Pavlovian conditioning. Pharmacol Biochem Behav 76:543-549. CrossRef Medline

Groenewegen HJ, Berendse HW, Haber SN (1993) Organization of the output of the ventral striatopallidal system in the rat: ventral pallidal efferents. Neuroscience 57:113-142. CrossRef Medline

Grueter BA, Robison AJ, Neve RL, Nestler EJ, Malenka RC (2013) FosB differentially modulates nucleus accumbens direct and indirect pathway function. Proc Natl Acad Sci U S A 110:1923-1928. CrossRef Medline

Haber SN, Groenewegen HJ, Grove EA, Nauta WJ (1985) Efferent connections of the ventral pallidum: evidence of a dual striato pallidofugal pathway. J Comp Neurol 235:322-335. CrossRef Medline

Hearing MC, Jedynak J, Ebner SR, Ingebretson A, Asp AJ, Fischer RA, Schmidt C, Larson EB, Thomas MJ (2016) Reversal of morphineinduced cell-type-specific synaptic plasticity in the nucleus accumbens shell blocks reinstatement. Proc Natl Acad Sci U S A 113:757-762. CrossRef Medline

Koob GF, Volkow ND (2010) Neurocircuitry of addiction. Neuropsychopharmacology 35:217-238. CrossRef Medline

Kravitz AV, Tye LD, Kreitzer AC (2012) Distinct roles for direct and indirect pathway striatal neurons in reinforcement. Nat Neurosci 15:816-818. CrossRef Medline

Kupchik YM, Scofield MD, Rice KC, Cheng K, Roques BP, Kalivas PW (2014) Cocaine dysregulates opioid gating of GABA neurotransmission in the ventral pallidum. J Neurosci 34:1057-1066. CrossRef Medline

Kupchik YM, Brown RM, Heinsbroek JA, Lobo MK, Schwartz DJ, Kalivas PW (2015) Coding the direct/indirect pathways by D1 and D2 receptors is not valid for accumbens projections. Nat Neurosci 18:1230-1232. CrossRef Medline

Laurent V, Morse AK, Balleine BW (2015) The role of opioid processes in reward and decision-making. Br J Pharmacol 172:449-459. CrossRef Medline

Lobo MK, Zaman S, Damez-Werno DM, Koo JW, Bagot RC, DiNieri JA, Nugent A, Finkel E, Chaudhury D, Chandra R, Riberio E, Rabkin J, Mouzon E, Cachope R, Cheer JF, Han MH, Dietz DM, Self DW, Hurd YL, Vialou V, et al. (2013) $\delta$ FosB induction in striatal medium spiny neuron subtypes in response to chronic pharmacological, emotional, and optogenetic stimuli. J Neurosci 33:18381-18395. CrossRef Medline

Lobo MK, Nestler EJ (2011) The striatal balancing act in drug addiction: distinct roles of direct and indirect pathway medium spiny neurons. Front Neuroanat 5:41. CrossRef Medline

Lobo MK, Covington HE 3rd, Chaudhury D, Friedman AK, Sun H, DamezWerno D, Dietz DM, Zaman S, Koo JW, Kennedy PJ, Mouzon E, Mogri M, Neve RL, Deisseroth K, Han MH, Nestler EJ (2010) Cell type-specific loss of BDNF signaling mimics optogenetic control of cocaine reward. Science 330:385-390. CrossRef Medline

Lu XY, Ghasemzadeh MB, Kalivas PW (1998) Expression of D1 receptor, $D 2$ receptor, substance $P$ and enkephalin messenger RNAs in the neurons projecting from the nucleus accumbens. Neuroscience 82:767-780. CrossRef Medline

MacAskill AF, Cassel JM, Carter AG (2014) Cocaine exposure reorganizes cell type- and input-specific connectivity in the nucleus accumbens. Nat Neurosci 17:1198-1207. CrossRef Medline

Mahler SV, Vazey EM, Beckley JT, Keistler CR, McGlinchey EM, Kaufling J, Wilson SP, Deisseroth K, Woodward JJ, Aston-Jones G (2014) Designer receptors show role for ventral pallidum input to ventral tegmental area in cocaine seeking. Nat Neurosci 17:577-585. CrossRef Medline

McFarland K, Kalivas PW (2001) The circuitry mediating cocaine-induced reinstatement of drug-seeking behavior. J Neurosci 21:8655-8663. Medline

Nakajima K, Cui Z, Li C, Meister J, Cui Y, Fu O, Smith AS, Jain S, Lowell BB, Krashes MJ, Wess J (2016) Gs-coupled GPCR signalling in AgRP neurons triggers sustained increase in food intake. Nat Commun 7:10268. CrossRef Medline

Olive MF, Anton B, Micevych P, Evans CJ, Maidment NT (1997) Presynaptic versus postsynaptic localization of $\mu$ and $\delta$ opioid receptors in dorsal and ventral striatopallidal pathways. J Neurosci 17:7471-7479. Medline

Panlilio LV, Goldberg SR (2007) Self-administration of drugs in animals and humans as a model and an investigative tool. Addiction 102:18631870. CrossRef Medline

Pascoli V, Turiault M, Lüscher C (2011) Reversal of cocaine-evoked synaptic potentiation resets drug-induced adaptive behaviour. Nature 481:7175. CrossRef Medline

Pascoli V, Terrier J, Espallergues J, Valjent E, O'Connor EC, Lüscher C (2014) Contrasting forms of cocaine-evoked plasticity control components of relapse. Nature 509:459-464. CrossRef Medline

Perry CJ, McNally GP (2013) A role for the ventral pallidum in contextinduced and primed reinstatement of alcohol seeking. Eur J Neurosci 38:2762-2773. CrossRef Medline

Peters J, Kalivas PW (2006) The group II metabotropic glutamate receptor agonist, LY379268, inhibits both cocaine- and food-seeking behavior in rats. Psychopharmacology (Berl) 186:143-149. CrossRef Medline

Phillips PE, Stuber GD, Heien ML, Wightman RM, Carelli RM (2003) Subsecond dopamine release promotes cocaine seeking. Nature 422:614618. CrossRef Medline

Pickel VM, Shobin ET, Lane DA, Mackie K (2012) Cannabinoid-1 receptors in the mouse ventral pallidum are targeted to axonal profiles expressing functionally opposed opioid peptides and contacting $\mathrm{N}$-acylphosphatidylethanolaminehydrolyzing phospholipase D terminals. Neuroscience 227:10-21. CrossRef Medline

Root DH, Ma S, Barker DJ, Megehee L, Striano BM, Ralston CM, Fabbricatore AT, West MO (2013) Differential roles of ventral pallidum subregions during cocaine self-administration behaviors. J Comp Neurol 521: 558-588. CrossRef Medline

Roth BL (2016) DREADDs for neuroscientists. Neuron 89:683-694. CrossRef Medline

Saunders BT, Yager LM, Robinson TE (2013) Cue-evoked cocaine "craving": role of dopamine in the accumbens core. J Neurosci 33:1398914000. CrossRef Medline

Schmidt HD, Anderson SM, Pierce RC (2006) Stimulation of D1-like or D2 dopamine receptors in the shell, but not the core, of the nucleus accum- 
bens reinstates cocaine-seeking behaviour in the rat. Eur J Neurosci 23: 219-228. CrossRef Medline

Self DW, Barnhart WJ, Lehman DA, Nestler EJ (1996) Opposite modulation of cocaine-seeking behavior by D1- and D2-like dopamine receptor agonists. Science 271:1586-1589. CrossRef Medline

Smith KS, Berridge KC (2005) The ventral pallidum and hedonic reward: neurochemical maps of sucrose "liking" and food intake. J Neurosci 25: 8637-8649. CrossRef Medline

Smith RJ, Lobo MK, Spencer S, Kalivas PW (2013) Cocaine-induced adaptations in D1 and D2 accumbens projection neurons (a dichotomy not necessarily synonymous with direct and indirect pathways). Curr Opin Neurobiol 23:546-552. CrossRef Medline

Stefanik MT, Kupchik YM, Brown RM, Kalivas PW (2013) Optogenetic evidence that pallidal projections, not nigral projections, from the nucleus accumbens core are necessary for reinstating cocaine seeking. J Neurosci 33:13654-13662. CrossRef Medline

Surmeier DJ, Ding J, Day M, Wang Z, Shen W (2007) D1 and D2 dopaminereceptor modulation of striatal glutamatergic signaling in striatal medium spiny neurons. Trends Neurosci 30:228-235. CrossRef Medline

Tang XC, McFarland K, Cagle S, Kalivas PW (2005) Cocaine-induced reinstatement requires endogenous stimulation of $\mu$-opioid receptors in the ventral pallidum. J Neurosci 25:4512-4520. CrossRef Medline

Tripathi A, Prensa L, Mengual E (2013) Axonal branching patterns of ven- tral pallidal neurons in the rat. Brain structure and function 218:11331157. CrossRef Medline

Wamsteeker Cusulin JI, Füzesi T, Inoue W, Bains JS (2013) Glucocorticoid feedback uncovers retrograde opioid signaling at hypothalamic synapses. Nat Neurosci 16:596-604. CrossRef Medline

Yawata S, Yamaguchi T, Danjo T, Hikida T, Nakanishi S (2012) Pathwayspecific control of reward learning and its flexibility via selective dopamine receptors in the nucleus accumbens. Proc Natl Acad Sci U S A 109: 12764-12769. CrossRef Medline

Zahm DS (1989) The ventral striatopallidal parts of the basal ganglia in the rat: II. Compartmentation of ventral pallidal efferents. Neuroscience 30: 33-50. CrossRef Medline

Zahm DS, Heimer L (1988) Ventral striatopallidal parts of the basal ganglia in the rat: I. Neurochemical compartmentation as reflected by the distributions of neurotensin and substance P immunoreactivity. J Comp Neurol 272:516-535. CrossRef Medline

Zahm DS, Zaborszky L, Alones VE, Heimer L (1985) Evidence for the coexistence of glutamate decarboxylase and Met-enkephalin immunoreactivities in axon terminals of rat ventral pallidum. Brain Res 325:317-321. CrossRef Medline

Zalocusky KA, Ramakrishnan C, Lerner TN, Davidson TJ, Knutson B, Deisseroth K (2016) Nucleus accumbens D2R cells signal prior outcomes and control risky decision-making. Nature 531:642-646. CrossRef Medline 